\title{
JOSEPH HODARA
}

Apuntes sobre la metahistoria de Marx

Con tres los propósitos enlazados de este escrito: a) caracteri$\$$ zar los rasgos principales de la metahistoria; b) indicar cómo se traducen en las proposiciones marxistas; $c$ ) sugerir condiciones epistemológicas y sociales que pueden procurarle legitimidad teórica. Al cabo señalaré que toda filosofía empirista de la historia contiene una metahistoria a menos que lidie, explícitamente, con el grave asunto de la "objetividad" y la "subjetividad" en la investigación histórica que ampliaré en otra oportunidad.

\section{Historia y metahistoria}

Algunos especialistas conocidos (Ranke, Fisher, Pirenne) han establecido que una historia particular se refiere a un espacio acotado de la experiencia humana (personaje, época, costumbres) que se verificó en el pasado; no tiene la pretensión de ofrecer un significado general o comprensivo; a lo sumo proporciona un relato interesante o una moraleja bien definida. Ciertamente, la sumatoria de historias particulares puede abrir cauce a una historia universal (del mundo, de una cultura); pero el significado último del ejercicio seguirá siendo empírico, con discretas implicaciones para la existencia presente. El historiador renuncia de antemano a los papeles de profeta, moralizador o ideólogo; si epígonos o futuras generaciones entusiastas le procuran esta fisonomía no es de su directa responsabilidad.

El caso de la metahistoria y de sus cultivadores es absolutamente distinto. Tenía razones A. Bullock al observar que esta estructura cognitiva rivaliza con la "verdadera" historia y conviene alejarse de ella. ${ }^{1}$ ¿Cuáles son sus caracteres y porqué ejerce un encanto - yencantamiento- especial en el público politizado

${ }^{1}$ Véase A. Bullock, "The Historian's Purpose: History and Metahistory", History Today, vol. 1,1, febrero 1951. 
y entre intelectuales que suelen mirar con tedio a la pormenorizada monografía histórica?

Uno es la globalidad, es decir, la formulación de leyes suficientes o necesarias - que permiten interpretar el curso universal de hechos y culturas con un paradigma breve y económico, forjado con algunas sentencias y relaciones. La metahistoria nos obsequia una sensación de omnipotencia: todo es comprensible, llano, sin vericuetos ni sutilezas. Omnipotencia que nos pone a salvo, por impertinente, del hallazgo singular, del dato imprevisto que tuerce el esquema aceptado a priori.

Otro carácter de la metahistoria es la facultad profética. No digo predictiva pues este adjetivo entraña un eslabonamiento causal riguroso, en tanto que la profecía está a mitad de camino entre el dato revelador y la adivinanza hechizante, apenas aclarada. $\mathrm{La}$ profecía adquiere verdad por un artilugio semántico: porque es dicha: no debe ser probada. ${ }^{2}$ De aquí que el señalamiento metahistórico se dirige, con gravedad, al futuro: orienta y alecciona.

Sigue el tercer rasgo: la metahistoria desborda el archivo, el gabinete, las fichas cuidadosamente ordenadas por personajes, periodos o tendencias. Llega a las tribunas y al discurso como una doctrina moralmente superior; pues no se conduce como una ideología para las masas (aunque éstas puedan banalizarla); la metahistoria demanda señuda comprensión y exposición. Es materia de exégesis con ejemplos selectivos tomados de la humilde historia.

La Biblia, San Agustín, Vico, Voltaire, Comte, Spengler, Toynbee propusieron metahistorias con esta triple intención. Desatienden la crónica, la búsqueda detectivesca del historiador, y el juicio provisional. Prefieren la generalización sentenciosa, el juego con metáforas, el remanso donde la narración, la literatura y la mística convergen.

Repárese: las metahistorias desempeñan indispensable papel. Aportan color y metáforas a las estaciones de la cultura; confieren significado trascendente a acumulaciones y secuencias de hechos; unen las dimensiones sacras, profanas y cotidianas de la humana experiencia en un haz; brindan al discurso público retazos de la memoria colectiva; y proporcionan guías y signos en la desolación social y en las reconstrucciones esperanzadas.

${ }^{2}$ R. Barthes, "Historical Discourse", en M. Lane (ed.), Introduction to Structuralism, Basic Books, New York, 1970. 


\section{La metahistoria marxista: la versión literal}

Cuando al historiador británico Christopher Hill se le preguntaba si era marxista, contestaba elusivamente: "¿quién es un historiador marxista?" Más tarde me refériré a este interrogante; ahora hay que inspeccionar a Marx y a su metafísica.

No digo metafísica por azar. Marx no fue sólo un hegeliano converso; Comte le suministró la idea de que es válida una ciencia social a imagen y semejanza de la física newtoniana, y, como la física, podía proponer una metafísica de la cual se derivarían relaciones y hechos. Y también creyó en el progreso industrial indefinido de Saint Simon que, por el juego astuto de la dialéctica, llevaría al socialismo, a la historia humana genuina.

En su Introducción a la Crítica de la Economía Política (1859) se encuentran los componentes de su metahistoria. Quienes ignoraron los textos importantes del "joven Marx" (como Lenin y Plejanov) se inclinaron a una exégesis literal de este escrito; en los treinta, Lukács, Bloch y Lefébvre - entre otros- debieron revisarlo. Referiré la interpretación ortodoxa pues ha influido y trastornado mucho más que aquéllas que guardan fidelidad a Marx. Nadie es invulnerable a la ironía del tiempo.

En la Introducción Marx distingue tres elementos básicos: a) las fuerzas de producción que incluyen a los medios de producción (materias primas, tecnologías, fuerza de trabajo, capacidad inventiva); b) la infraestructura o base "concreta" que contiene a las relaciones de producción, relaciones atingentes a la propiedad que determinan a su turno las pautas de trabajo en diferentes tipos de sociedad. Las relaciones de producción revisten rasgos estructurales: clases $-\mathrm{y}$ no nexos personales - se organizan y pugnan en torno a ellas. Y para culminar el argumento: las fuerzas y las relaciones de producción constituyen un modo de producción, cuya variación da lugar a diferentes estructuras históricas; c) la infraestructura tiene un techo: la "superestructura", que cobija a las categorías legales, políticas y artísticas.

Es mérito de Marx e infortunio del marxismo ortodoxo que este esquema sea moneda corriente. No precisa por consiguiente elaboraciones. Sólo indicaré un problema interesante: la ciencia. ¿Es parte de la superestructura o es medio de producción? La respuesta no es tajante. Si la ciencia es una manifestación de la cultura y sólo por azar e indirectamente apareja innovaciones técnicas, pertenece al aparato ideológico; pero en las condiciones del capitalismo y del socialismo maduros la ciencia tiene utilidad social, en buena medida, porque es, a la corta o a la larga, tec- 
nología. Entonces, es medio de producción. ¿No podrá argüirse lo mismo del arte y de las ideologías masificadas?

Pero retengamos el andamiaje inicial. Conforme a éste, las relaciones de producción están ... (se abre la polémica: "¿condicionadas?" "¿determinadas?" "¿vinculadas?") unidas, por algrin orden de causalidad, con las fuerzas de producción. Y cuando brota el conflicto entre ellas (pues la tecnología industrial es dinámica: recuerden a Saint Simon) despunta un cambio de sistema económico. La dialéctica de las acumulaciones no sólo tiene un inicio: es teleológica.

\section{La metahistoria marxista: la versión crítica}

Trataré de finalizar el examen de las propiedades de este sistema. Algunos comprobarán por este camino su fecundidad teórica; y otros, su estatura mística.

Primero, la postulación de leyes. La adyacencia entre fuerzas de producción y relaciones de producción aparejaría un ritmo histórico. Cuando el maridaje es bueno, el periodo (o la cultura) está exenta de sobresaltos; pero al sobrevivir la pugna, despunta una revolución social. Dicha de otra manera, no sólo las clases y las ideas sino la misma ley están sometidas a la dialéctica. Y la ley histórica tiene categoría epistemológica semejante a la de la física (influencia de Comte), es decir, es necesario; nadie ni nada puede alterarla. Esta postulación de la ley necesaria es la médula del determinismo histórico, que se ramifica en cuatro premisas básicas: a) la historia se rige por leyes; $b$ ) los factores económicos son determinantes del ritmo y de la dirección de la historia; $c$ ) los procesos históricos son lógica y estructuralmente necesarios; $d$ ) el conocimiento de las leyes permite prever el futuro, al menos el inmediato.

Segundo, la historia es una secuencia de acumulaciones y conflictos provocados por la acción y la arritmia de las fuerzas de producción y de las relaciones de producción. Pero esta secuencia no es lineal; no es mera duración en el tiempo que carece de estaciones y de un término concreto, ni es tampoco circular al modo de un "eterno retorno". La trayectoria histórica es una espiral, hecha de ascendentes acumulaciones-fricciones. La historia progresa (la fe comtiana) pero con paros y arranques, conforme a las cuatro premisas enunciadas previamente.

Tercero, si la historia, que se despliega a manera de espiral, tiene una última estación, un telos que justifica sus accidentes y demencias, ¿́cuál es? La metahistoria marxista secularizó la fan- 
tasía apocalíptica. Marcha necesariamente, merced a leyes estructurales, hacia un propósito trascendente - el socialismo- que acaba con la enajenación humana e inicia un nuevo Período (con mayúscula). El telos fundamenta retrospectivamente, y por su calidad, el camino andado, los periodos finalizados. Pero en contraste con el brete apocalíptico o la floración mesiánica, la metahistoria marxista presenta un cuadro científico - experimental de la última etapa histórica, y moviliza a los hombres a obtenerlo en nombre de una moral superior.

Finalmente, todos estos postulados conforman una metafísica que Plejanov denominó "materialismo dialéctico", para contrastarla con el idealismo hegeliano. El acento de Marx en las fuerzas y en las relaciones de producción fue interpretado por sus epígonos como la "materia" que da forma y sustancia a la naturaleza y a la historia.

La metafísica es materialista en un sentido también particular. Las necesidades primarias (hambre, sexo, escasez) gobiernan a la conducta individual, mientras que factores económico-sociales animan a las ruedas del colectivo. Unas y otras son "materia". Por tanto, la metahistoria es un caso especial del materialismo dialéctico, y éste se articula en una metafísica "de lo concreto" que privilegia a los imperativos primarios de la existencia natural y humana.

\section{4. ¿Quién es historiador marxista?}

Ahora se puede ensayar una respuesta: aquél que en la narrativa histórica, en el ordenamiento causal de los hechos, en la interpretación de significados y en la adjudicación de responsabilidades a los actores históricos utiliza postulados de esta metafísica. Quiero decir, primero, la creencia en leyes que permiten explicar el carácter y la dinámica de culturas y periodos; segundo, la explicación de los hechos conforme a la dialéctica de las fuerzas y de las relaciones de producción y la manera en que éstas se "reflejan". en ideologías (superestructuras); tercero, la deducción de sucesos que podrían haber ocurrido con alta probabilidad de acuerdo con el interjuego de acumulaciones conflictivas; y en fin, el pronóstico de hechos y tendencias con apego a la dinámica dialéctica.

Es importante disipar un prejuicio. La narración histórica efectuada según la metahistoria de Marx no es por fuerza "tediosa", "aburrida", "previsible". Puede gestar investigaciones pormenorizadas, amenas y hasta sorprendentes, a semejanza de historia- 
dores que siguen a Spengler o a Toynbee, dueños de una metafísica mucha más sencilla y vulnerable que la de Marx. Un historiador puede ser "interesante" independientemente de la filosofia histórica especulativa que lo orienta. Si posee imaginación, espíritu detectivesco para el detalle y la inferencia, además de sensibilidad literaria, puede imprimir calor a una crónica enfadosa o a un pedestre eslabonamiento de accidentes.

\section{La legitimidad intelectual de la metahistoria marxista}

Después de presentar brevemente las premisas de la interpretación dialéctica de la historia, creo que tengo fundamentos para establecer que esta metahistoria posee una riqueza epistemológica ponderable a pesar de que fue dilapidada vergonzosamente en regímenes que dijeron representarla. Más todavía: esta metafísica de telos humanista justificó actos de violencia y asesinato al tiempo que la rebajó a niveles triviales en el discurso y en la reflexión.

Pero su legitimación cognitiva es reversible. Involucra varias condiciones. Una de ellas es la libertad intelectual, prenda de la que gozó el propio Marx al establecer su estancia en 1851, en Londres, hasta su muerte (1883). Como esta condición no cristaliza en regímenes totalitarios o dogmáticos (pueden ser países enteros o universidades de naciones democráticas), la reivindicación de Marx sólo puede ocurrir, por la astucia de las paradojas, en países capitalistas avanzados y en centros de estudio que toleran el fluido canje de ideas. No es casualidad que las corrientes neomarxistas (Gramsci, Adorno, Marcuse, Frömm) florecieran en sociedades abiertas o en una prisión (como las ideas del italiano menudo y genial) a salvo del terrorismo estalinista.

La segunda condición es el replanteo de las categorías que componen a la metahistoria. Ya se insinuó que ciencia y arte han dejado de ser "superestructuras" debido a la utilidad tecnológica de la primera y a la masificación comercial de la segunda. El paradigma debe entonces rectificarse.

La tercera condición es atenuar en la metafísica marxista el cientificismo comtiano y la fe inquebrantable en el progreso industrial. Wittgenstein, Popper, los estudios del Club de Roma: éstos debieran ser los correctores del optimismo y de la epistemología ingenuos de Marx.

$\mathrm{Y}$ en fin, el mesianismo social de Marx debe absorber mayor ecuanimidad. La historia carece de una estación terminal discernible, a menos que algunos hombres, ajenos a todo conflicto de 
clases, decidan ponerle fin con la tecnología apocalíptica que tienen en sus manos. Si este mesianismo se relaja o atenúa, entonces la violencia autoritaria que en buena medida engendró se tornará prescindible y contraproducente. Y con más libertad y menos violencia se parirá una certera historiografia, más fiel a la disciplina científica y a la aventura humana.

\section{6: Coda}

No debe entenderse de aquí que puede generarse una historia sin metafísica o sin juicios de valor, explícitos o indirectos. La tarea del historiador es demasiado humana. Sus aciertos y debilidades impregnan a la narración histórica. Sin embargo, el conocimiento histórico debe alcanzar la certificación pública de todo conocimiento, es decir, un relato o interpretación ganan credibilidad en la medida en que obtienen el apoyo argumentado y relativamente unánime de los especialistas. Apoyo transitorio, ciertamente. Porque nuevos hallazgos o razonamientos pueden modificar opiniones consagradas. Pero la búsqueda permanente de esta certificación compartida es el recaudo de la objetividad del discurso histórico.

Esta condición no excluye a la inevitable subjetividad. Es muy importante establecerle límites para preservar la limpieza del texto histórico. Desde Ranke a Collingwood se ha insistido en que la empatía, la capacidad de identificarse con el protagonista, debe ser una prenda del historiador. En una acepción ingenua, esta facultad involucra la comprensión internalizada - no necesariamente justificadora en el plano ético - de las motivaciones, contextos y guiones de los actores históricos. Sin embargo, es indudable que el horizonte de referencia del historiador es completamente distinto al de estos actores. La empatía es, por lo tanto, siempre discreta y discriminatoria; hay acontecimientos - por ejemplo, un genocidio - que la excluyen terminantemente.

Aparte de la empatía, el historiador debe poseer el talento de "traducir" a los términos de su cultura el lenguaje particular de la historia "de los otros". Este asunto pertenece a la adyacencia entre historia y antropología. ¿Cómo puede "descifrar" un inglés moderno a un romano clásico? ¿O un blanco a un negro? ¿O un nacionalista a un místico? ¿Es viable tal desciframiento? En principio, sí. El requisito es el dominio del método científico y una "fantasía disciplinada" capaz de capturar emociones y lógicas extrañas. 
En tercer lugar, un buen historiador no puede eludir juicios de valor. Ya están presentes en la elección del tema estudiado. Y más concretamente, en la explicación de los hechos, en la causalidad con que los interpreta y ordena, y en la adjudicación de responsabilidades a los actores históricos. En todas estas acciones el historiador pondera, enjuicia, sentencia. Para que su quehacer no sea arbitrario debe atenerse a la exploración y al cotejo cuidadosos de los acontecimientos y a la descripción esmerada de procesos, señalando las normas éticas y estéticas que presiden su labor.Si no asume este riesgo, el historiador se transforma en un "cronista", en un registrador mecánico de hechos, que se abstiene de interpretar y aleccionar dentro de los cánones rigurosos de la disciplina científica.

Estos enunciados entrañan que no hay forma de eludir a la metahistoria. Sólo cabe hacerla limpia y explícita. Y si el historiador cree que se constriñe "sólo" a los hechos, lectores inteligentes de la historia le probarán su error, reinventando el texto y las secuencias de su historia en un juego borgiano infinito. 